\title{
EL ESCUDO DE ITALIA. EL EJÉRCITO DE LOMBARDÍA, CLAVE DEL PODER ESPAÑOL EN LA PENÍNSULA ITALIANA (1560-1700)
}

\author{
DaVide MAFFi \\ Università di Pavia
}

RESUMEN. En el periodo entre 1560 y 1700, el ejército de Lombardía era el segundo ejército en importancia de la monarquía española. El fuerte presidio acuartelado en el Estado de Milán permitía no solo el control de los accesos a la península italiana, ejerciendo el papel de antemural de los reinos de Nápoles y de Sicilia, sino también una rápida conexión con los primos vieneses de los Austrias y con las llanuras alemanas. Todo ello sin olvidar el papel de Milán como punto de partida del camino español. Esta presencia de miles de hombres armados inevitablemente comportó un aumento de las cargas fiscales en el Milanesado, de manera que las comunidades locales fueron llamadas a contribuir cada vez más al esfuerzo bélico de la monarquía. En consecuencia, a partir de la década de los cuarenta el país pagó prácticamente las dos terceras partes del gasto militar y todavía más en la segunda mitad del siglo XVII. A pesar de las duras críticas, tanto de los contemporáneos como de la historiografía decimonónica, el ejército de Lombardía supo garantizar el predominio español en Italia y siguió representando una fuerza bien organizada y eficiente en el campo de batalla hasta finales del siglo XVII.

Palabras clave: Estado de Milán, ejército de Lombardía, camino español, fiscalidad militar, alojamientos

ABSTRACT. During the period between 1560 and 1700, the Army of Lombardy represented the second most important army of the Spanish monarchy. The strong garrison quartered in the State of Milan allowed not only the control of the accesses to the Italian peninsula, thus exercising the role of bulwark of the kingdoms of Naples and Sicily, but also a quick connection with the Viennese cousins of the Habsburgs and the German plains. Without forgetting the role of Milan as the starting point of the Spanish road. A presence of thousands of soldiers that inevitably led to an increase in fiscal charges with the Milanesado with the local communities

Recibido: 25-01-2021 . Aceptado: 2-05-2021 . davide.maffi@unipv.it 
that were called to contribute in an increasingly forceful way to the war effort of the monarchy. With the country than from the decade of the Forty paid for practically two-thirds of military spending and in the second half of the seventeenth century even more. Despite harsh criticism, both from contemporaries and from nineteenth-century historiography, the Lombard army until the end of the seventeenth century was able to guarantee Spanish predominance in Italy and continued to represent a well-organized and efficient force on the battlefield.

Keywords: State of Milan, Army of Lombardy, Spanish Road, fiscal-military state, barracks

\section{La clave de Italia (1560-1589)}

Ya en las primeras décadas del siglo Xvi el gran canciller imperial, Mercurino Gattinara, había subrayado la importancia del control del estado de Milán, cuya posesión permitía mantener una vía de comunicación abierta entre el mundo Mediterráneo y los territorios hereditarios de la casa de Austria en el Sacro Imperio Romano. Además de esto, en palabras de Gattinara, garantizándose el señorío de este Estado su majestad cesárea podía asegurar la defensa del reino de Nápoles, objeto de un largo desafío entre el emperador y el rey de Francia, transfiriendo la lucha a la llanura Padana y dejando al reino libre de cualquiera amenaza directa (Chabod, 1971a, pp. 19-22).

De hecho, el control imperial de la Lombardía gracias a la gran victoria en la batalla de Pavía (1525), dejaba al duque Francesco II Sforza como legítimo señor de Milán, aunque transformado en un criado del emperador, con unos márgenes de maniobra reducidos al mínimo. La muerte del duque en el mes de noviembre de 1535 dejaría las manos prácticamente libres a Carlos V, que rápidamente incorporó el ducado a los dominios imperiales.

A partir de esta fecha la posesión de este territorio fue estratégicamente basilar en la política del emperador, de modo que Milán sirvió de baluarte adelantado frente a las penetraciones francesas en Italia, de freno a los príncipes italianos y como punto de enlace con los dominios alemanes (Chabod, 1986, pp. 185-217). Una posición central que no se modificó con el ascenso de Felipe II al trono del Milanesado, en el culmen de las luchas con Francia de los años cincuenta, de modo que seguiría revistiendo un papel fundamental en la estrategia del nuevo soberano (Rodríguez-Salgado, 1994).

Se puede afirmar tranquilamente que la posición central de esta región en la estrategia de la monarquía se incrementó durante el reinado de Felipe II, cuando, con motivo de la rebelión de los Países Bajos, este Estado antemural de Italia se transformó en el principal centro logístico para enviar refuerzos a Bruselas. A partir de 1567, cuando el duque de Alba inauguró el susodicho Camino Español, que desde la Lom- 
bardía atravesaba los pasos de Suiza y las llanuras de Alemania occidental llegando a Bruselas (Parker, 2004, pp. 70-90), miles de hombres recurrieron esta ruta en un intento de acabar exitosamente la lucha con las provincias rebeldes.

Así, si el control de los Países Bajos era fundamental en la política europea de la Corona, y ello convertía a España en una gran potencia a nivel continental (Parker, 1994, p. 121; Israel, 1997, pp. 63-64), a partir del reinado del rey prudente la preservación del Estado de Milán era complementaria en la estrategia general europea de la monarquía: sin Milán no se podían defender las provincias septentrionales ni intervenir eficazmente en Alemania. Gracias al Milanesado se mantenían abiertas las rutas de comunicación entre el Mediterráneo y el centro de Europa; se podían enviar refuerzos a Flandes; se reforzaban las relaciones entre Madrid y Viena (gracias a los pasos alpinos que permitían el paso de tropas y dinero para socorrer a los primos vieneses); y se garantizaba la hegemonía española en la península italiana, en virtud de la presencia de una poderosa guarnición militar que protegía a la región y que servía también para poner freno a los deseos de los príncipes de Italia. Por último, aunque no menos importante, la conservación de Milán, como había sucedido en el curso de las guerras de la primera mitad del siglo XVI, aseguraba también la defensa de los reinos meridionales de Italia, haciendo de aquel un antemural de los reinos de Nápoles y Sicilia (Rizzo, 2007, pp. 467-511; Álvarez-Ossorio Alvariño, 2007, pp. 99-132).

Para asegurar el control y la defensa de este territorio, clave para la política de la monarquía no solo en Italia, en la región se instaló ya en tiempos del emperador Carlos un fuerte dispositivo militar, necesario para hacer frente al estado de guerra permanente contra los franceses, que desde 1536 habían asumido el control de gran parte del Piamonte, manteniendo así una pistola apuntada al corazón de Lombardía (Rabà, 2016; Guinand, 2020). Ya con las ordenanzas de Génova (1536) el emperador había puesto las bases de una estructura militar permanente en las posesiones italianas, con la creación de los tercios de Lombardía, Nápoles y Sicilia (Quatrefages, 1996). Además, los territorios peninsulares asistieron a la reorganización de las estructuras burocráticas militares: una vez dotadas las regiones de una guarnición estable era necesario desarrollar la estructura logística, los oficios encargados de abastecer, pagar y controlar la compleja maquinaria militar que se estaba creando en Italia, y en particular en el Milanesado. Una organización que acabó de definirse a principios del reinado de Felipe II, cuando en Milán se completó el proceso de constitución de los oficios del sueldo y se reorganizaron y remodelaron las viejas oficinas del estado de los Sforza encargadas de atender los aspectos logísticos (Maffi, 2002).

El fin de las guerras de Italia con la paz de Câteau-Cambrésis (1559) supuso una notable contracción del dispositivo militar hispano en la región, proporcionando un cierto alivio a los súbditos lombardos, que durante tantos años habían tenido que 
contribuir de manera notable al esfuerzo bélico manteniendo las huestes reales ${ }^{1}$. Sin embargo, dada la extrema importancia de este territorio en la compleja estrategia general del rey prudente, el país no quedó desguarnecido de fuerzas. Las órdenes reales preveían el mantenimiento en la región de un tercio de infantería española, el susodicho tercio de Lombardía, de unas cuantas compañías de caballería, las lanzas, la antigua caballería pesada feudal, y la caballería ligera, además de las compañías de la guardia del gobernador y de los presidios ordinarios encargados de defender las fortalezas $^{2}$. En total una fuerza militar nada despreciable, dado que en el interior del Milanesado se reunían unos 6.000 efectivos, en un territorio de alrededor de 16.000 kilómetros cuadrados con una población de poco menos de 1.000.000 de habitantes, una fuerza que absorbía un porcentaje relevante, casi las dos terceras partes, de todos los ingresos del Estado ${ }^{3}$.

Como hemos visto, la eclosión de la rebelión en los Países Bajos transformó el Milanesado en un centro logístico fundamental para el mantenimiento del conflicto en el norte de Europa. Recordaremos solo como desde 1567, fecha de la marcha del duque de Alba, hasta 1607, año en que se selló el primer alto el fuego, 119.297 hombres cruzaron el territorio lombardo con destino a Bruselas (Parker, 2004, pp. 237-238). En Lombardía, como en Nápoles, las unidades de bisoños completaban su formación militar antes de ser desplazadas a los diversos frentes de guerra, de manera que Geoffrey Parker afirmó que el servicio militar prestado en los presidios de Italia era «the seminary in which the invincible Spanish tercios were made» (Parker, 1990, p. 33).

Frente a las necesidades de la guerra en el norte, de la amenaza turca en el Mediterráneo, que asistió a una fuerte movilización de fuerzas en la década de los

1 Los datos disponibles indican como en tiempo de guerra, que a partir de 1535 fue prácticamente una constante en la región, se acuartelaron en Lombardía más de 30.000 hombres, con picos más de 40.000 (veáse, Chabod, 1971b, pp. 321, 328, 331; Maltby, 1983, p. 90).

2

Archivo General de Simancas (en adelante AGS), Estado, legajo 1.212, doc. 142, Las ordenanzas de Su Majestad para los gastos del ejército de Piamonte y Lombardía desde primero del año de 1561 en adelante y lo que monta un mes de sueldo, 24 de diciembre de 1560. En 1560 la dotación ordinaria de los Presidios (Milán, Plasencia, Cremona. Alejandría, Pavía, Tortona, Lodi, Pizzighettone, Abbiategrasso, Vigevano, Novara, Rocca de Arona, Domodossola, Como, Lecco, Trezzo, Pontremoli), fue fijada en 1.411 soldados sin los oficiales de la primera plana: AGS, Estado, legajo 1216, doc. 87, Relación particular de la gente que reside y ordinariamente se paga en los castillos del Estado de Milán y con vecinos y personas particulares y otros ministros y oficiales que con ellos se pagan en la manera siguiente, sin fecha (pero 1564). El número de presidios varió en las décadas siguientes, cuando se abandonaron algunas posiciones, como Piacenza, y se construyeron nuevas fortalezas con una dotación fija que se modificó en consecuencia. A partir del siglo XVII la dotación de los presidios se estabilizó alrededor de los 1.800-2.000 hombres (Maffi, 2010, pp. 97-98).

Recordaremos solo como en 1560 el gasto mensual de la gente de guerra comportaba el pago de unos 37.224 escudos mensuales, suma que no comprendía el pago de los presidios ordinarios, cuando los ingresos totales suponían poco más de 540.000 escudos (moneda de Milán) al año: AGS, Estado, leg. 1212, doc. 142, cit. (a este respecto véase también Maffi, 2007, p. 343). 
setenta ${ }^{4}$, y a la no menos importante obligación de preservar una pieza básica en el cuadro estratégico de la monarquía, la presencia militar hispana en la región se incrementaría, a veces casi doblando la dotación ordinaria fijada tras el fin de las guerras de Italia. Una serie de factores que, como hemos visto, rápidamente convertirían al Estado de Milán en la base del segundo ejército en importancia de la monarquía (Ribot García, 1994, p. 70). No podemos ofrecer aquí un cuadro exhaustivo de las continuas variaciones de las fuerzas de presidio, aunque basta recordar que solo en 1581 servían el rey en Milán más de 8.600 soldados $^{5}$. En el mes de junio del año siguiente se contabilizaban 7.293 soldados en tres tercios de infantería española, dos de ellos destinados a Flandes, y un tercio de infantería italiana, también destinado a los Países Bajos: una fuerza considerable en la cual no se incluían los soldados de caballería ni las dotaciones ordinarias de los presidios ${ }^{6}$.

Tal concentración de hombres hacía de Milán uno de los territorios más militarizados de la Europa occidental. El poderoso instrumento militar que componía el presidio era particularmente imponente, no solo en comparación con las fuerzas de los demás príncipes italianos, que solían contar con un puñado de hombres para garantizar la seguridad de sus estados, sino también con las fuerzas de otros soberanos europeos. Recordaremos solo como el duque de Saboya, considerado siempre el más aguerrido de los príncipes italianos, podía contar con unas fuerzas mucho más reducidas, poco menos de 1.000 hombres en 1564 y unos 1.500 en 1580 (Barberis, 1988, p. 66; Bianchi, 2002, p. 74). Por lo que se refiere a Venecia, el más poderoso de los antiguos estados peninsulares, mantenía en sus presidios de tierra firme unos 1.500-2.000 efectivos, reservando la mayoría de sus fuerzas terrestres para la defensa del imperio marítimo (Hale, 1990, 225). A título de comparación, recordaremos también que el rey de Francia mantenía en tiempos de paz no más de 15.000 hombres,

4 El Comendador mayor de Castilla en el mes de mayo de 1572 recordó los esfuerzos hechos por parte de la tesorería de Milán durante el año anterior para abastecer, pagar y armar las huestes reales empeñadas en la guerra contra el turco: AGS, Estado, legajo 1.235, doc. 30, el comendador mayor de Castilla al rey, 31 de mayo de 1572. En los cinco años de gobierno del conde de Ayamonte (1573-1578) la tesorería de Milán pagó 1.930 .230 escudos a la gente de guerra, dinero en gran parte remitido desde Castilla: AGS, Estado, legajo 1.249, doc. 159, Relatione delli denari che si sono spesi e pagati nella Thesoreria generale dello Stato di Milano dal principio del governo dell'Ill.mo Et Ecc.mo signor Marchese di Ayamonte che fu a mezzo del mese di settembre dell'anno 1573 sino a questo giorno 14 di luglio 1578 per gente di guerra, arme, munitioni, funditioni di artiglieria et altre cose per li regni di Spagna, Sicilia e Sardegna et per li Stati di Fiandra et altre parti, quali spese non erano a credito di questo Stato et si sono fatte parte delli danari che sono stati remessi per detti effetti et parte di denari di detto stato secondo le occasioni et necessità che sono occorse, sin fecha (pero 1578)

5 AGS, Estado, legajo 1.254, doc. 154, Relación de la gente de guerra, oficiales y personas que se entretienen y sirven a Su M.d en el exército de Lombardía y Piamonte y castillos del Estado de Milán, y sueldo que monta cada mes, sin fecha (pero 1581).

6 AGS, Estado, legajo 1.256, doc. 110, Lo que monta el pagamento que en 16 de este presente mes de junio se ha hecho a los tres tercios que de presente están en este estado y los soldados que cada uno de ellos tiene, 29 de junio de1582. 
repartidos en un territorio treinta veces más grande que Lombardía (Wood, 2002, pp. 52, 63-65), mientras las fuerzas de la reina de Inglaterra eran todavía más reducidas (Manning, 2006, pp. 3-40).

Esta militarización del territorio dio lugar a una serie de nuevas contribuciones, creadas para poder garantizar el sustento de la gente de guerra, y a pesadas cargas para alojar a las tropas. Impuestos como el Mensuale y el Tasso della cavalleria se crearon explícitamente para hacer frente a estas necesidades. En particular el Mensuale, que preveía el reparto en el territorio del estado de un impuesto de 300.000 escudos, sería utilizado en los decenios siguientes a su establecimiento para reunir todas las contribuciones de carácter militar: alojamientos, socorros, tren de artillería etc., dividiendo el peso entre todas las comunidades del Estado7.

Pese a la creación de nuevos impuestos, los ingresos ordinarios del Estado nunca consiguieron, incluso en los años tranquilos, hacer frente a las necesidades de la maquinaria militar, y desde otros territorios de la corona — principalmente desde Castilla y Nápoles, en menor medida desde Sicilia—, se enviaron importantes socorros a Milán. Por lo tanto, fue necesario enajenar parte del patrimonio regio para hacer frente a los gastos y ya en la segunda mitad del siglo xvI, tiempo que se benefició de la ausencia de guerras, se pudo observar un creciente deficit spending en las arcas del Milanesado (Rizzo, 1995, pp. 303-361). La falta crónica de dinero, una constante en la historia de la hacienda lombarda, obligó desde el principio a las autoridades hispanas a intentar descargar parte de los costes de la defensa sobre los súbditos milaneses. Desde los albores de la dominación española estos debieron hacerse cargo de una larga serie de obligaciones de carácter militar. En primer lugar, la de alojar a los soldados ${ }^{8}$, entregándoles, además de alojamientos, una serie de utensilios (camas, sábanas, muebles, etc.), los forrajes para los animales y, también satisfacer unas pretensiones extra de unos huéspedes poco agradecidos (Rizzo, 2001). En particular, los alojamientos y sus métodos dieron un triste renombre al Milanesado y, de hecho, la decisión del conde duque de Olivares de introducir el sistema lombardo, mucho más pesado y exigente con los súbditos, en Cataluña en 1640 fue una de las causas de la rebelión del Principado (Elliott, 1984, p. 405).

El mensuale era un nuevo impuesto introducido en tiempos del emperador Carlos $\mathrm{V}$ para el sustento de la gente de guerra. Se conformó definitivamente en 1547, cuando el gobierno fijó dicha contribución en 25.000 escudos mensuales, de ahí el nombre. La importancia de esta tasa consistía en el hecho de que su reparto entre los varios territorios del Estado (ciudades, condados, terre separate, etc.) constituyó la base de reparto de todas las futuras cargas militares. Sobre su introducción y repartimiento (véase, Vigo, 1979, passim).

«Fu sempre incombenza di questi sudditi il dare l'alloggiamento tanto in tempo di pace come di guerra a tutta la soldatesca che si trovava in questo Stato, e questo fu pratticato in ogni tempo, come si vede da vari ordini e pramatiche antiche et moderne»: AGS, Secretarías Provinciales, legajo 1.983, doc. 57, Sobre la instituzione del Rimplazzo e continuazione d'esso, sin fecha (pero posterior a 1685). 
Además de todo esto, en años de emergencia se obligaría al Estado a pagar la soldada y aprovisionar las tropas extraordinarias (las unidades que se habían juntado además del presidio ordinario), bajo la amenaza de permitir a los hombres «vivir a discreción» a cargo de los habitantes ${ }^{9}$. El problema del aprovisionamiento y del pago a las tropas en tránsito en este territorio surgiría en varias ocasiones en tiempos de Felipe II con unidades destinadas a los Países Bajos, siendo causa de fuertes enfrentamientos entre las comunidades del Estado y el gobernador (Rizzo, 2001, pp. 73-78).

En general, estos servicios de la segunda mitad del siglo fueron aceptados por parte de las comunidades bajo la fórmula de donativo voluntario, a condición de que no pudieran ser transformados en un cargo fijo, de manera que su concesión sería el resultado de largas negociaciones entre el gobernador y los representantes de dichas comunidades. Además, las comunidades lucharon para que el dinero entregado a la gente de guerra fuese descontado de las cargas ordinarias, obteniendo la promesa de que las sumas adelantadas serían reembolsadas condonando futuros impuestos ${ }^{10}$.

\section{El corazón de la monarquía (1590-1630)}

La vuelta de la guerra a las fronteras italianas se produjo tras la ocupación del marquesado de Saluzzo por parte del duque de Saboya, Carlos Emanuel I. A la ocupación del marquesado, territorio francés, se unió entonces el deseo del duque de intervenir en las cuestiones de Francia, para construir un reino independiente (Merlin, 2004, pp. 16-61; Merlin, 2018, pp. 48-84). Un proyecto que había acaparado desde hacía tiempo toda la atención del duque, llevándolo a la invasión de Provenza a finales de 1590 (Micallef, 2014, pp. 71, 74, 80-81). Esta política agresiva forzaría la intervención de Felipe II a favor de su aliado para hacer frente a los asaltos franceses, concentrando un gran número de tropas para oponerse a las ofensivas galas en las fronteras alpinas. Entre 1590 y 1598 miles de soldados y millones de escudos se destinaron a la defensa de las posesiones del duque de Saboya en una larga y estéril guerra fronteriza con el estado de Milán, obligando a realizar esfuerzos hercúleos para levantar, armar y mantener a miles de hombres. En total las fuerzas del ejército de Piamonte y Lombardía superaron en varias ocasiones los 15.000 efectivos, con repuntes de más de 25.000 (Maffi, 2018, pp. 417-446).

9 Hecho que ocurrió en varias ocasiones durante las guerras de Carlos V (véase, Chabod, 1971b, pp. 257 ss.).

10 Archivio Storico Civico Milano (en adelante ASCMi), Dicasteri, busta 167, sin foliar, Sostanza dell'informatione fatta a viva voce dalli delegati dello Stato di Milano alla Gionta de Ministri deputati a sentire la risposta dello Stato med.mo, 22 de abril de 1690. 
La llegada del conde de Fuentes a Milán a principios de siglo iba a impulsar una actitud más agresiva en el norte de Italia en contra de los «enemigos» de la monarquía, para restablecer el prestigio de la corona en contra de todos aquellos estados italianos que en las últimas dos décadas se habían alejado de la tradicional alianza española. A ello también contribuyó la política ambivalente del duque de Saboya, que cada día más se aproximaba a las posiciones de Enrique IV de Francia (Cano de Gardoqui, 1973, pp. 565-595; Bombín Pérez, 1978, pp. 153-173; Gal, 2012). Además, también se estaba produciendo un cambio en la estrategia general de la monarquía, que con el valimiento del duque de Lerma estaba volviendo a una política más Mediterránea (García García, 1996; Allen, 2000). Todos estos factores hicieron que Milán asumiese el papel de corazón de la monarquía, centro de gravedad de la política internacional de la corte (Fernández Albaladejo, 1993, pp. 185-237).

Para hacer frente a las amenazas y a las necesidades de la política italiana, a principios del siglo XVII se tomó la decisión de incrementar el dispositivo militar fijo en la región creando un nuevo tercio, el tercio de Saboya, que doblaba prácticamente el dispositivo militar español en el área. Esta resolución, fuertemente respaldada por Pedro Enríquez de Acevedo, conde de Fuentes, nuevo gobernador del Estado a partir de 1600, fue adoptada para asegurar el control de las vitales vías de comunicación con los Países Bajos, en peligro después de que en la paz de Lyon (1601), Carlos Emanuel I cediera a Enrique IV parte de sus territorios al otro lado de los Alpes (Cano de Gardoqui, 1962). También se hizo para asegurar el control de los pasos de la Valtellina, que a partir de 1605, empezaron a ser utilizados para trasladar tropas al corazón de Europa (Marrades, 1943; Maffi, 2005a, pp. 467-472).

Además de esto, en tres ocasiones, dos veces para contrastar las renovadas actitudes agresivas de Francia (1601 y 1610) y la tercera para apoyar a la Santa Sede en su conflicto con Venecia en la cuestión del interdicto (1607), el conde de Fuentes movilizaría ejércitos de unos 30.000 hombres. Pero también en años tranquilos, gracias al ya citado aumento de la dotación ordinaria, el ejército de Lombardía siguió siendo un instrumento formidable. Recordaremos como en el mes de marzo de 1603 la región acuartelaba dos tercios de infantería española y uno de napolitana, además de las fuerzas de caballería y de los presidios ordinarios; en total unos 9.200 solda$\operatorname{dos}^{11}$. Parecido era el nivel de las fuerzas en el mes de marzo de 1605, cuando servían en armas 6.923 soldados españoles en los dos tercios ordinarios; suma a la que habría que añadir la fuerza de los presidios y de la caballería ${ }^{12}$. Más reveladora todavía era la situación de enero de 1606, cuando estaban instalados en Lombardía unos 9.000 infantes españoles, además de la dotación fija de los presidios y de la caballería or-

11 AGS, Estado, legajo 1.292, doc. 56, Muestra general del ejército, sin fecha (pero marzo de 1603).

12 AGS, Estado, legajo 1.898, doc. 149, consulta del Consejo de Estado, sin fecha (pero abril de 1605) 
dinaria del Estado; lo que suponía que el Milanesado debía hacerse cargo de unos 12.000 hombres en total ${ }^{13}$.

Estas amenazas de guerra, pese a todos los preparativos hechos en tiempos del conde de Fuentes, no llegaron a concretarse, aunque no tardarían en manifestarse a principios de la década siguiente, cuando el duque de Saboya atacó el Monferrato, dando lugar a la primera guerra de Sucesión de Mantua y Monferrato (1613-1617) ${ }^{14}$. La participación española en este conflicto supuso la movilización de grandes ejércitos, de modo que entre 1614 y 1617 fueron reclutados contingentes de más de 30.000 hombres, con picos superiores a los 40.000, como ocurrió en el mes de junio de 1615 cuando prestaban servicio en el ejército de Lombardía más de 44.000 soldados (Mesa Gallego, 2020, pp. 138-150).

La actuación de estas fuerzas no ha gozado nunca de buena publicidad. La visión general de la decadencia de las capacidades militares de la monarquía durante el siglo XVII afectó también la conducción de esta guerra. Mal dirigidos, sin una clara visión estratégica, con unos oficiales ineptos, las fuerzas reales no supieron acabar el conflicto contra una mediana potencia con una rotunda victoria, de modo que la paz, al restablecer el estatus quo anterior, dejó bastante mermado el prestigio militar hispano (Bombín Pérez, 1975, pp. 235-260).

Es verdad que el ejército de Milán padeció una serie de inconvenientes que ayudaron a que el conflicto se prolongase. Problemas como la falta de una jerarquía de mando bien definida, de modo que los generales luchaban entre ellos por cuestiones de precedencia; la ineptitud del marqués de la Hinojosa como general, y una conducción de la guerra desde Madrid complicada por la actitud y las maniobras políticas del duque de Lerma, que dejaron a los altos mandos hispanos sin una guía coherente. En realidad, en el campo de batalla las huestes reales prácticamente ganaron todas las batallas y su actuación fue muy apreciada, consiguiendo destrozar todos los intentos del duque de Saboya y de sus aliados de poner pie firme en el Monferrato (Mesa Gallego, 2020, pp. 152-153).

La paz de Pavía (1617) no significó el fin de las turbulencias, que golpearían continuamente al Estado de Milán en los decenios siguientes. La eclosión de la guerra de los Treinta años, con la intervención de los Austrias de Madrid al lado de los primos de Viena, después de la defenestración de Praga, un episodio destinado a pro-

13 AGS, Estado, legajo 1.296 doc. 30, el conde de Fuentes al rey, 22 de enero de 1606.

14 Originalmente analizada por la historiografía romántica nacionalista decimonónica como el primer intento de la casa de Saboya de actuar por la libertad de Italia, en realidad fue un conflicto internacional, el primer acto de aquel conflicto mejor conocido como la guerra de los Treinta años y prólogo de la crisis política general a la que fue sometida Europa a mitad del siglo y hasta la paz de los Pirineos. Sobre la polarización del conflicto, en el que participaron activamente varias potencias europeas, enviando dinero y soldados al duque de Saboya, remito a las consideraciones expuestas por Merlin (2016, pp. 15-29) y Ferretti (2016, pp. 31-46). 
vocar una guerra generalizada en el Sacro Imperio Romano Germánico de trágicas consecuencias, hizo que aumentara la importancia de Milán a los ojos de la cúpula político militar de la monarquía. Milán se convirtió así en retaguardia indispensable para suministrar refuerzos y auxilios a los aliados alemanes, centro de reclutamiento de primera importancia, clave de Italia y, como siempre punto de partida del camino español hacia Flandes.

Un papel que el Estado supo desarrollar a partir de los primeros años de guerra, con el tránsito de las tropas italianas destinadas a unirse al ejército del conde Tilly para intervenir en la batalla de la Montaña Blanca, y con la ocupación de la Valtellina (1620), valle de capital importancia estratégica para permitir las comunicaciones entre el norte de Italia y el sur de Alemania y, sobre todo, con Bruselas (Aldea Vaquero, 1998, pp. 3-21; Barrio Gozalo, 1998, pp. 23-51).

Por todas estas razones una ofensiva contra este territorio estaba destinada a convertirse en uno de los objetivos principales de la estrategia del cardenal Richelieu, que conocía bien la relevancia de la región a ojos de la cúpula política de Madrid, de modo que en varias ocasiones se refirió a la Lombardía como del verdadero point faible del sistema imperial Habsburgico (Externbrink, 2000, pp. 181-208; Externbrink, 2014, pp. 2014). Para él, era necesario un ataque contra el Milanesado para obligar a la monarquía a empeñar las reservas y evitar así que los soldados hispanos se concentrasen en Flandes, desde donde podían amenazar directamente el centro del poder francés, y para interrumpir las vitales líneas de comunicaciones españolas con el centro de Europa (Tapié, 1989, p. 288).

Debido a esta política, ya en 1624-26 — siguiendo la estrategia de cortar las vitales líneas de suministros españolas en un momento delicado de la lucha en los Países Bajos, con el marqués de Spinola empeñado en el sitio de Breda, y en Alemania - los franceses habían intentado poner un pie en Italia, enviando un ejército en apoyo de los planes del duque de Saboya contra Génova y ocupando la Valtelina. Pero sus intentos habían fracasado por la resuelta contraofensiva española, apoyada en la movilización de las escuadras de galeras y la concentración en Milán de un ejército de unos 40.000 hombres (Elliott, 1986, pp. 222-241).

Los franceses tendrían más éxito en la segunda guerra de Monferrato (162831 ), cuando se apoderaron de la fortaleza de Pinerolo, garantizando así el libre paso de sus fuerzas a las llanuras de Piamonte, y pusieron una guarnición en Casale Monferrato, ciudad que guardaba uno de los pasos del rio Po y se encontraba a corta distancia de Milán, por lo que amenazaba directamente la integridad de las posesiones hispanas en el norte de Italia (Elliott, 1988, pp. 106-109; Koenigsberger, 1971, pp. 243-244).

La segunda guerra por la sucesión de Mantua - que asistió a un cambio repentino en la política del duque Carlos Emanuel I que, habiendo vuelto a la tradi- 
cional alianza española, mudó rápidamente de parecer tras la entrada de las tropas de Luis XIII en Saboya-, estaba destinada a exaltar la posición privilegiada de Milán en el sistema hispano. Empezando como una fácil campaña militar, el sitio de Casale Monferrato se transformó pronto en una pesadilla destinada no solo a originar una guerra no concluyente, cuando no desastrosa, sino también a absorber todos los recursos disponibles (Parrott, 1997, pp. 20-65). Hombres y dinero, necesarios más que nunca en Flandes para contener la ofensiva holandesa, se enviaron a Milán. En un momento particularmente delicado de la guerra en los Países Bajos ${ }^{15}$, la necesidad de concentrar todos los recursos en defensa de las posiciones italianas había provocado en Madrid un cambio sustancial de prioridades: durante los años 1628 y 1629 las de Flandes fueron sacrificadas para permitir la conservación y la defensa del Milanesado.

Una preeminencia en el plan estratégico general que Milán conservaría en los años siguientes. Todavía en 1632 el conde duque de Olivares afirmaba que, enfrentado a una elección extrema, había preferido sacrificar los estados de Flandes antes que el Estado de Milán, reafirmando así el papel central de la región en el sistema estratégico de la monarquía (Signorotto, 1989, p. 194).

Para salvaguardar la seguridad de este bastión estratégico fundamental, a finales de la década de los veinte y principios de los treinta, en Lombardía se acuartelaron ejércitos de alrededor de 30.000 hombres y a veces muchos más. Así eran más de 37.000 los hombres en servicio en mayo de $1629^{16}$. Todavía había más de 29.000 efectivos en el mes de junio de $1629^{17}$, y en marzo de 1632, una vez desmovilizado el ejército después de la firma de la paz de Cherasco, estaban en servicio más de 15.500 soldados $^{18}$.

15 Después del triunfo de Breda la situación en la frontera norte había empezado a cristalizarse en una guerra de posición, la diversión de Casale Monferrato permitió a los holandeses tomar la iniciativa y en 1629 cayó la plaza de 's Hertogenbosch. En decenios esta fue la primera vez en que los españoles fueron obligados a ceder terreno frente al avance holandés, pérdida acrecentada en 1632 por la caída de Venlo y Maastricht (véase, Vermeir, 2006, pp. 36-44 y 61-66; Esteban Estríngana, 2005, pp. 178 ss).

16 AGS, Secretarías Provinciales, legajo 1.803, doc. 150, Relación sumaria del ex.to de Lombardía en 26 de mayo $1629 .$. , sin fecha (pero mayo de 1629).

17 AGS, Estado, legajo 3.437, doc. 157, Relación del número de oficiales y soldados..., 10 de junio de 1630 .

18 AGS, Estado, legajo, 3830, doc. 283, Relación de los oficiales y soldados que se han presentados y hechos buenos en la muestra que se ha tomado en 20 marzo de 1632 a los tercios de infantería napolitana y lombarda..., 8 de abril de 1632; AGS, Estado, legajo, 3830, doc. 284, Relación de los oficiales y soldados que se han presentados y hechos buenos en los infrascritos dos tercios de infantería española en la muestra que se les ha tomado en 30 de marzo de $1632 . ., 8$ de abril de 1632; AGS, Estado, legajo, 3830, doc. 285, Relación de los oficiales y soldados que hoy día de la fecha se hallan claros y buenos en sus asientos en las infrascritas compañias de caballería del estado, 8 de abril de 1632; AGS, Estado, legajo, 3830, doc. 286, Relación de los oficiales y soldados que se han presentado y hechos buenos en la muestra que se ha tomado en 6 de abril de 1632 a los dos regimientos de infantería alemana..., 10 de abril de 1632. 
Pese a la importancia de las fuerzas desplegadas, la actuación de las fuerzas armadas de la monarquía fue notablemente inferior a las expectativas. Si durante las operaciones llevadas a cabo en la campaña de 1625 las huestes reales demostraron mantener grandes capacidades operativas, frustrando los planes del cardenal Richelieu, no se puede decir lo mismo de los ejércitos de algunos años después ${ }^{19}$. No solo no consiguieron apoderarse de la vital fortaleza de Casale Monferrato, sino que también se crearon notables fracturas en la cadena de mando, de modo que la marcha de las operaciones militares se vio paralizada en varias ocasiones por las rivalidades intestinas (Fernández Álvarez, 1955). Como ocurrió con ocasión de la primera guerra de Monferrato, faltaba una estructura jerárquica bien definida, de modo que el ejército contaba con cuatro maestros de campos generales, ninguno de los cuales gozaba del título de maestre de campo general del ejército de Lombardía, provocando la competencia entre ellos y que no fuesen obedecidos por los demás generales de la caballería y de la artillería del Estado ${ }^{20}$.

Desde el punto de vista de las relaciones con las comunidades locales, en estas décadas la obligación de alojar y socorrer estas masas de hombres aumentó notablemente la pesada carga sobre las comunidades y en este periodo se intentó en varias ocasiones transformar los servicios para la gente de guerra de actos voluntarios ocasionales a imposiciones obligatorias. De hecho, el intento del conde de Fuentes, a su llegada a Milán (1601), de generalizar el pago del socorro a la tropa transformándolo en una nueva imposición ordinaria se enfrentó con la dura resistencia de las autoridades milanesas, por lo que el conde se vio obligado a revocar esas disposiciones (1603) (Giannini, 1997, p. 198).

Sin embargo, en los decenios siguientes, las continuas guerras y emergencias de la primera mitad del siglo XVII agudizaron este problema y llevaron a los representantes de la corona a institucionalizar una serie de medidas «extraordinarias», transformándolas de ocasionales a permanentes. Ejemplos de esta política se habían producido ya con ocasión de la primera guerra por la sucesión de Monferrato (1613-1617), cuando don Pedro de Toledo, presionado por la falta de dinero y el

19 No existe ningún estudio moderno sobre las operaciones militares llevadas a cabo por las fuerzas de Felipe IV en el norte de Italia durante estos años. El clásico trabajo de Quazza (1926) ofrece una visión demasiado descriptiva de los acontecimientos y en muchas ocasiones falta de objetividad, proponiendo una visión risorgimentale del asunto y exagerando mucho el papel de la casa de Saboya, cual paladina de la causa italiana en contra de los opresores españoles. Citado aparece también el libro de Fernández Álvarez (1955), que además analiza solo la actitud del gobernador de Milán, Gonzalo Fernández de Córdoba, en los primeros meses del conflicto. El análisis de la política española en la región en esta década clave se ha visto comprometida por la falta de documentación en los archivos españoles. En el Archivo General de Simancas los papeles del fondo Estado sobre los asuntos italianos se interrumpen en 1622 y no hay casi ninguna documentación sobre el conflicto. 
retraso en la llegada de socorros, obligó a las comunidades a pagar la soldada a los presidios (Maffi, 2007, p. 369). Unos años después, don Gonzalo de Córdoba, frente a la necesidad de movilizar el ejército para sitiar Casale Monferrato, dio disposiciones para que las comunidades pagasen no solo los gastos de alojamiento, sino también las pagas, socorros y forrajes del ejército, hasta entonces competencia de la Real Hacienda ${ }^{21}$. Una medida que fue aceptada solo como contribución provisional y absolutamente extraordinaria, y bajo la cláusula de que el dinero anticipado debía ser descontado del pago de los demás impuestos y en particular del Mensuale $^{22}$. El intento de transformar en 1632 este pago en una imposición obligatoria en tiempo de paz naufragó frente a la dura oposición del Estado, que hizo notar como «da un atto volontario dello Stato non si deve, ne puol ridurre una legge di contratto» ${ }^{23}$.

Sin embargo, el aumento de la carga militar, que llegó a niveles asombrosos con millones de escudos gastados en estos años ${ }^{24}$, hizo que ya a finales del siglo XVI, las autoridades empezaran una serie de reformas para repartir de manera más

21 ASCMi, Dicasteri, busta 167, sin foliar, Sostanza dell'informatione fatta a viva voce..., doc. cit.

22 «Con otra cantidad como importaba la suma que les estaba repartida pareciendo muy conforme a razón y justicia que pues esta contribución (está destinada como está) para los socorros de la gente de guerra se suponía gastada en ellos se le admitiese a las tierras la compensación quando se llegase a ajustar la quenta de lo socorrido»: voto del Consejo de Italia, 19 de abril de 1628 reproducido en AGS, Estado, legajo 3.848, doc. 113, consulta del Consejo de Estado, 17 de mayo de 1643.

23 ASCMi, Dicasteri, busta 167, sin foliar, Sostanza dell'informatione fatta a viva voce..., doc. cit.

24 Las guerras en la frontera del Piamonte en los años noventa supusieron el pago de sumas cercanas al millón de escudos al año. Recordaremos solo lo ocurrido en la campaña de 1595, cuando el condestable de Castilla, entonces gobernador, salió del estado para socorrer el Franco Contado de Borgoña, agredido por parte de las tropas de Enrique IV. En esa ocasión el mantenimiento del ejército supuso el desembolso de 1.189.405 escudos: AGS, Estado, legajo 1.283, doc. 41, Sumario sucinto de lo del dinero gastado y lo que Su M.d debe, sin fecha (pero 1597). Entre el 1608 y el 1617 el Estado de Milán lamentó que solo el alojamiento y utensilios entregados a las fuerzas reales conllevó un gasto de más de 16.000.000 de escudos, suma que no comprendía las contribuciones ordinarias ni tampoco otros cargos extraordinarios que las comunidades tuvieron que pagar, como el pago del tren de artillería, que supuso el pago de otros 86.760 escudos a partir de 1614, como también el socorro a la gente de guerra que muchas localidades tuvieron que anticipar para permitir a las tropas salir en campaña: AGS, Secretarías Provinciales, legajo 1.834, doc. 257, Información del Estado de Milán para el Supremo Consejo de Italia de los socorros y pagas dadas a los soldados y daños padecidos de 12 años a esta parte y de los medios para su satisfacción, sin fecha (pero 1620). La movilización de tropas consecuente al ataque francés a la Valtellina y en contra de Génova comportó un gasto mensual de unos 360.000 escudos mensuales para pagar al ejército: AGS, Secretarías Provinciales, legajo 1.802, doc. 244, Consulta del Consejo de Italia, 17 de enero de 1626. Por fin, recordaremos como en 1629 se calculaban necesarios más de 216.000 escudos al mes para pagar solo el pan de munición, el socorro de la tropa y una paga entera a la caballería y a los regimientos alemanes: AGS, Secretarías Provinciales, legajo 1.803, doc. 150, Relación sumaria del ex.to de Lombardía en 26 de mayo 1629..., sin fecha (pero mayo de 1629). Ante tales costes no sorprende que en 1634 la deuda total contraída por parte del Estado de Milán, fundamentalmente para hacer frente al peso de la gente de guerra, ascendiese a 22.628.401 escudos: AGS, Estado, legajo 3.341, doc. 276, Consulta del Consejo de estado, 18 de agosto de 1634 . 
igualitaria las cargas militares entre las distintas tierras del Estado, obligando a las ciudades a contribuir en una cierta medida ${ }^{25}$.

A partir de los años setenta las comunidades menos favorecidas solicitaron un mejor reparto de las cargas, consiguiendo algunos notables éxitos gracias al apoyo interesado de las autoridades de gobierno, empeñadas en la constante búsqueda de nuevos fondos para el ejército. En 1597 se instituyó la Egualanza generale, por medio de la cual se instituía una cámara de compensación de los gastos, de modo que las provincias y tierras que no habían tenido que hacerse cargo de los alojamientos de tropas, tenían que pagar una compensación a las comunidades menos afortunadas (Rizzo, 2003, pp. 469-538). Este fue un primer paso importante para obligar a las ciudades a contribuir de manera más decisiva al esfuerzo bélico de la monarquía, paso que sería seguido en los años siguientes por la pérdida de una serie de privilegios, como el de no alojar a las tropas, de modo que en 1610 el conde de Fuentes obligaría a varias ciudades a acuartelar fuertes contingentes de tropas (Maffi, 2007, pp. 280-285)

\section{Tiempos de crisis (1631-1660)}

La paz de Cherasco no cambió mucho el cuadro estratégico de la península italiana, que a partir de 1635 se convirtió en otro escenario del desafío franco-español. En los primeros años de este largo conflicto el ejército de Lombardía actuó de forma ofensiva, llevando la guerra al corazón de los dominios del duque de Saboya. En los planes del conde duque de Olivares, a partir de 1637 el Milanesado tenía que actuar lanzando vigorosos ataques para abrirse camino hacia el corazón del Piamonte y, una vez vencida la resistencia del duque de Saboya, penetrar en Francia.

En realidad, las ofensivas españolas de los años 1637 y 1638 no consiguieron resultados definitivos: a pesar de la toma de Vercelli (1638) no culminaron los planes de finalizar la guerra en el norte de Italia. Solo la campaña de 1639 pareció resolver la situación a favor de España, permitiéndole acabar de manera más que favorable la lucha en la península. A finales de este año los franceses parecían totalmente aniquilados y la corte de Saboya paralizada y dividida, con las huestes reales en Turín y las principales plazas del duque presidiadas por soldados del rey (Maffi, 2020b, p. 237).

25 Aparece oportuno subrayar que el Estado de Milán conservaba todavía leyes típicas de un estado ciudadano; las capitales provinciales mantenían amplias autonomías con respecto al gobierno central y ejercitaban un fuerte control sobre su territorio, los contadi. Las ciudades gozaban además de la prerrogativa de no alojar las tropas en virtud de antiguos privilegios otorgados durante los siglos XIV y XV por parte de los duques de Milán (Chittolini, 1979; Covini, 1992, pp. 1-56). Así las ciudades no solo no alojaban, sino que descargaban todos los cargos de naturaleza militar sobre las espaldas de sus contadi, una situación que permaneció inalterada durante los primeros decenios de la dominación española. 
Sin embargo, las victorias conseguidas durante este año marcaron el límite de la penetración hispana en el Piamonte y la derrota padecida bajo las murallas de Casale Monferrato y la pérdida de Turín en el transcurso de la campaña siguiente hicieron naufragar los sueños de acabar rápidamente la contienda.

En realidad, fue la eclosión de la rebelión de Cataluña, que modificó totalmente las prioridades estratégicas de la monarquía con consecuencias casi fatales para el mantenimiento del conflicto en la región, la que supuso un cambio definitivo en la evolución de la guerra en Italia. A partir de este momento Milán fue relegada a una posición marginal, ante la necesidad de recuperar el Principado rebelde: el Estado ya no era el corazón de la monarquía sino un frente segundario en los trágicos acontecimientos de la década de los cuarenta (Maffi, 2020b, p. 238).

Con estos cambios en la estrategia general de la monarquía derivados de la sublevación catalana, a partir de 1641 Milán fue la gran olvidada, un frente de guerra secundario con respecto a Flandes, en donde continuó concentrándose la fuerza militar principal de la corona, y con respecto a Cataluña, pese a que la región continuó manteniendo el segundo ejército en importancia de la monarquía ${ }^{26}$.

Después de la derrota de Montjuich, sustraer veteranos españoles, y no solo ellos, al ejército de Lombardía se transformó en una constante, según los principios básicos de una nueva estrategia general bien expresada en una frase de don Miguel de Salamanca: «primero es procurarse ajustar las cosas de España que conservar otras provincias» (Parker, 1986, p. 48).

Este nuevo dogma que preveía dar la precedencia a la situación peninsular fue reafirmado en varias ocasiones en los años siguientes. A este propósito baste recordar como en el mes de octubre de 1643 el Consejo de Estado tomó la decisión de sacrificar Lombardía a favor de una ofensiva en Cataluña ${ }^{27}$. En palabras de los condes de Monterrey y de Oñate, la defensa de Milán y el mantenimiento del ejército de Piamonte y Lombardía a partir de este momento debía encomendarse a los propios lombardos y al reino de Nápoles, puesto que no se podía esperar ningún tipo de ayuda de Castilla. Además, se pedían hombres y dinero a ambas provincias para reforzar el dispositivo militar desplegado en la frontera aragonesa ${ }^{28}$. Esta decisión tomada en el otoño de 1643 tendría consecuencias fundamentales en la conducción de la guerra en el norte de Italia en los años siguientes hasta el fin del conflicto.

Por lo tanto, a partir de 1641 los gobernadores de Milán se quedaron sin hombres ni dinero para poder asegurar no solo el mantenimiento de una guerra ofensiva en

26 A pesar de la contracción en el número de las tropas disponibles, con más de 30.000 hombres en los años treinta, con más de 40.000 efectivos durante la campaña de 1639, en el Milanesado se mantuvieron siempre huestes cercanas o superiores a las 20.000 unidades (véase, Maffi, 2007, pp. 136-137)

27 AGS, Estado, legajo 3.848, doc. 154, Consulta del Consejo de Estado, 23 de octubre de 1643.

28 AGS, Estado, legajo 3.838, doc. 138, Consulta del Consejo de Estado, 6 de octubre de 1643. 
el Piamonte, sino la defensa del mismo Estado (Maffi, 2020b, pp. 239). Las instrucciones enviadas desde Madrid ya no hablaban de hipotéticas grandes ofensivas, sino de efectuar unas cuantas diversiones en contra de los franceses para que no enviasen fuerzas a Cataluña. O, sobre todo a partir de 1644, se limitaban a sugerir a los capitanes generales que se sucedieron en Milán que actuasen con prudencia para asegurar la defensa del territorio sin arriesgarse a enfrentarse el enemigo en batallas campales.

Así, el Estado tuvo que afrontar prácticamente solo las grandes ofensivas galas de 1647 y 1648, cuando el cardenal Mazarino hizo de Milán uno de los objetivos principales de su estrategia ofensiva. La decisión del valido francés debe leerse a la luz de los fracasados intentos de conseguir una victoria total en Cataluña, lo que obligó al cardenal a cambiar su estrategia general, haciendo de Milán el objetivo principal de la campaña (Stradling, 1992, pp. 160-161). Unas ofensivas destinadas a fracasar bajo las murallas de Cremona, cuando por dos veces las tropas españolas consiguieron derrotar a las fuerzas galas (Maffi, 2007, pp. 44-47).

La paz de Westfalia no modificó sustancialmente este cuadro estratégico general: se seguía prefiriendo Cataluña a Milán. A pesar de la marginación del papel del Estado de Milán, evidente con la caída de Breisach y el fin del camino español y la rebelión de Cataluña, parece oportuno subrayar que este continuó durante toda la guerra ejerciendo su tradicional papel de antemural de Nápoles y foco del poder militar hispano en Italia.

Además, la rendición de Barcelona y el fin de la Fronda en Francia tendrían grandes repercusiones también en Milán. En primer lugar, porque desde España se podían enviar soldados y dinero a Lombardía en mayor medida que en años anteriores. En segundo término, porque el cardenal Mazzarino pudo reemprender sus proyectos de una ofensiva a gran escala en Italia, a imitación de lo que había hecho en 1647 y 1648 y abandonó a causa de la guerra civil (Blum, 2014, pp. 355 ss.). Como en los primeros años del largo desafío franco-español, el Estado volvía a ser otra vez el centro de la lucha entre las dos potencias. Conseguida la recuperación del principado catalán, en Madrid el Milanesado recuperaba parte de su importancia en el sistema defensivo hispano en Europa.

Las grandes ofensivas galas, lanzadas a ritmo sostenido sobre todo después de 1654, cuando Mazarino consiguió convencer otra vez al duque de Módena de tomar las armas en contra de Felipe IV (Blum, pp. 309-310), dieron lugar a una serie de enfrentamientos continuos para lograr el control de la región. Los grandes triunfos, como el de Pavía en 1655, se mezclaron con terribles derrotas, como la pérdida de Valenza en 1656, cuando, por primera vez desde 1645, el enemigo ponía pie sólidamente en el interior del Estado, y Mortara (1658).

Este estado de guerra permanente obligó a las autoridades españolas a aumentar de manera exponencial el peso de las contribuciones a cargo de los súbditos lom- 
bardos para compensar la merma constante en los envíos de socorros desde Madrid y Nápoles ${ }^{29}$. Ya hemos visto como en los decenios precedentes, al perdurar el clima de inestabilidad debido a la eclosión de la guerra contra Francia (1635) y su larga duración hasta la paz de los Pirineos, esta disposición había pasado de circunstancial a permanente, obligando a las ciudades a contribuir de manera directa alojando a las tropas del rey. A partir de 1641, ante el constante hundimiento de los socorros provenientes de otros reinos, que privó a las autoridades milanesas de gran parte del efectivo necesario para poder hacer frente a los gastos de guerra, se decidió que el Estado debía hacerse cargo de los cuarteles invernales (unos seis meses al año), costeando el normal alojamiento de las tropas y todos los gastos relativos a las pagas, socorros y forrajes. A título de compensación por este servicio, introducido también en esta ocasión como un donativo voluntario ${ }^{30}$, la Real Hacienda perdonaba a las tierras todos aquellos impuestos de carácter militar (mensuale, tasso della cavalleria, tasso d'ambedue le cavallerie, 14 reali) introducidos a lo largo del siglo anterior para el mantenimiento del ejército (Maffi, 2007, pp. 369-370).

Al salir de los cuarteles invernales el comisario general del ejército, después de ver las muestras hechas por parte del veedor general, calculaba el gasto diario del mantenimiento de las tropas, repartiéndolo entre las ciudades y pueblos según las cuotas del mensuale. Gracias a este reparto el Magistrato Ordinario, el supremo organismo fiscal y financiero del Estado, cobraba el dinero de las diferentes comunidades y se lo entregaba a la tropa ${ }^{31}$. De esta manera los gobernadores de Milán

29 Si durante los primeros años de guerra, hasta 1640, desde Madrid se pudieron enviar sumas importantes de más de 1.000.000 de ducados, a partir de 1641 los ingresos de la tesorería de Milán se contrajeron de manera constante: durante los años cincuenta las remesas se habían reducido a unos 300.000 escudos. Una situación similar ocurrió con los envíos desde Nápoles, de modo que el reino vio reducirse progresivamente sus envíos, quedándose en poca cosa después de 1646. Solo en los años finales del conflicto se pudo asistir a un retorno de las remesas napolitanas hacia Milán, si bien en cantidades notablemente inferiores respecto al pasado (véase, Maffi, 2007, pp. 344-346).

30 «Non è (come forse viene supposto) tributo camerale di S. M. ${ }^{\text {tà }}$, in modo che questo possa in ogni tempo per mezzo di qualsiasi esattore, forriere, o commissario esigersi, o riducendo in una sol cosa, o portarlo dall'uno, all'altro luogo di Provincia in Provincia, e di Città in Provincia, o sij in quartiere forzato, o sij in campagna; ma è quel forzoso et estremo sussidio che per l'allegata impotenza del R. Erario, suole l'amore de sudditi con proportion tanto ineguale alle sue forze, e con singolare esempio e differenza d'ogni altro de vasti Dominij di S. M. ${ }^{\text {tà }}$ significare al buon servicio della medema»: ASCMi, Dicasteri, busta 167, sin foliar, Sostanza dell'informazione fatta a viva voce..., doc. cit.

31 De este reparto quedaba excluida la ciudad de Milán, gracias al antiguo privilegio que la exceptuaba de alojar tropas. Un privilegio que fue confirmado a cambio del pago de su cuota del Mensuale, más o menos 100.000 escudos al año (unos 110.000 reales de a ocho). El Magistrato Ordinario no cobraba directamente el dinero sino que enviaba las relaciones a las ciudades y tierras, a las que tocaba decidir sobre los medios para satisfacer el coste. A las varias Congregazioni dei Contadi, organismos de representación de las ciudades y tierras del Estado (en Milán existían 9 Congregazioni, una por cada ciudad y condado), correspondía después el repartimiento de la suma y su efectiva recaudación: AGS, Secretarías Provinciales, legajo 2.010, doc. 1, memorial de la Congregazione dello Stato, sin fecha (pero 1687). 
garantizaban la supervivencia del aparato bélico, pero al precio de sobrecargar a las comunidades lombardas de gravámenes que suponían un gasto cuatro, cinco o incluso más veces superior a lo que importaban los impuestos suprimidos ${ }^{32}$. Desde 1650 hasta 1660 las pagas, socorros y forrajes de la tropa, sin contar los demás desembolsos - tren de artillería, gastos de dicha arma, remonta de la caballería, sueldo de oficiales generales y otros..., que en estos años se cargaron directamente sobre los hombros de los súbditos milaneses (Maffi, 2007, pp. 370-384)—, según lo que indican los repartimientos hechos por el oficio del comisario general, comportaron un gasto diario de 24.000 a 26.000 liras, llegando casi a las 30.000 liras en 1655, y nunca bajaron de las 21.500 liras (nivel mínimo alcanzado en 1651) (Ribot García, 1990, pp. 214-221; Maffi, 2010, p. 282).

Se puede afirmar tranquilamente que la supervivencia de la Lombardía española durante estos años de verdadera crisis se debe a un conjunto de factores. En primer lugar, a la actuación del ejército, que no fue nunca aquella masa esclerótica dibujada varias veces por la tradición de la historiografía decimonónica, de modo que supo contrarrestar eficazmente las ofensivas galas en la región casi hasta el final de la contienda. Secundariamente, debido a las enormes contribuciones pagadas por parte de la gente del país, que a partir de 1641 se hizo cargo de las dos terceras partes, y a veces mucho más, de todos los gastos de guerra.

\section{La plaza de armas (1661-1700)}

El fin de la guerra no supuso para Milán la recuperación de aquella posición de preeminencia de la que había gozado hasta 1640 en el sistema estratégico hispano. El final del camino de Flandes quitaba al Estado aquel papel de retaguardia de Flandes y la necesidad de defender la península Ibérica, en particular la frontera catalana, de las continuas agresiones de Luis XIV, modificó sensiblemente el papel de Milán a los ojos de los dirigentes políticos de la monarquía. Ciertamente la provincia siguió alojando al segundo ejército en importancia de la corona, conservó su posición como antemural de Nápoles y mantuvo su carácter de defensora de los intereses españoles en la llanura Padana y por esto hasta finales del siglo jugó todavía un papel importante en el complejo y difícil sistema político italiano (Maffi, 2010, pp. 17-45).

Los enormes sacrificios pedidos a los fieles súbditos lombardos durante la guerra hicieron que el Estado de Milán a partir de 1660 solicitase con insistencia una

32 El descuento de las dichas tasas comportaba un ahorro para las comunidades del orden de poco menos de 300.000 escudos al año (unos 330.000 reales de a ocho). En una relación (incompleta, porque omitía varios cargos) enviada desde Milán en el curso de 1653, la ciudad se lamentaba de que las cargas militares introducidas en los últimos años habían comportado un gasto de 6.256.411 liras imperiales (más de 1.250.000 reales de a ocho): British Library, Egerton, Mss. 530, folios. 25-31, súplica de la ciudad de Milán, sin fecha (pero de 1653). 
fuerte disminución del dispositivo militar hispano, de manera que quedase reducido al tamaño del siglo anterior, cuando Felipe II ordenó mantener en la región una fuerza de unos 5-6.000 hombres ${ }^{33}$. Estas peticiones fueron aceptadas por la cúpula político-militar de la monarquía, que redujo las fuerzas a solo 4.000 infantes y 2.000 caballos (Maffi, 2010, pp. 46-47).

El alivio debido a la contracción del dispositivo militar en la región fue solo momentáneo: la política agresiva de Luis XIV impuso rápidamente un cambio radical en las dimensiones del presidio español. Ya en 1667, con la eclosión de la guerra de Devolución, se movilizaron varios miles de hombres para el ejército, que pasó de tener poco más de 7.700 soldados en febrero de 1666 a unos 11.500 en octubre de 1668. Con la ocasión de la guerra de Holanda se tuvieron que levantar varias unidades nuevas y Milán juzgó un papel clave en la retaguardia. Un papel que resultó indispensable para sostener el esfuerzo bélico en Sicilia, a donde se enviaron miles de hombres, y en el intento de defensa del Franco Contado de Borgoña en 1674. En estos años el país tuvo que mantener siempre huestes superiores a los 10.000 hombres, con repuntes de más de 15.000 al final de la guerra. La ocupación de Casale Monferrato por parte de las tropas galas en 1681 hizo de Milán una nueva frontera crítica, con los franceses cerca del corazón del país, lo que obligó a aumentar el número de tropas hasta superar los 20.000 hombres durante la guerra de Luxemburgo. La participación española en la guerra de los Nueve años provocaría un nuevo y fuerte aumento en el dispositivo militar hispano, al mantenerse en armas más de 20.000 soldados (Storrs, 1997, pp. 371-399; Storrs, 1998, pp. 1-22; Maffi, 2020a, pp. 126-128).

Esta considerable fuerza supo dar buena cuenta de su potencial durante el conflicto. El contingente español empeñado en Piamonte era, sin duda, el más numeroso y mejor equipado de las tropas aliadas y su actuación fue fundamental para apuntalar las posiciones aliadas. En particular, durante la toma de Casale Monferrato (1695), ya que 14.000 de los 22.000 soldados empleados eran hombres del rey de España, que suministró también la casi totalidad del tren de la artillería. Un episodio que minó de manera considerable el prestigio de Luis XIV en la península itálica y fue una clara señal de que España conservaba una soberbia capacidad militar en la región (Maffi, 2020a, pp. 128-129).

Ya hemos visto cómo el peso del ejército durante las guerras contra Francia dejó al país en una situación apurada en extremo, tanto que al final de la guerra el Estado no solo pidió una considerable reducción del aparato militar, sino también capacidad para intervenir directamente en la gestión y control de los gastos. Tras la presión ejercida por parte de los representantes del Milanesado, en 1662 don Luis Guzmán Ponce de León, entonces gobernador, llevó a cabo una verdadera revolución

33 Archivo Histórico Nacional (en adelante AHN), Estado, legajo 1.902, sin foliar, consulta del Consejo de Italia, 12 de marzo de 1660. 
en la materia, dando forma definitiva al sistema introducido por la vía extraordinaria algunos decenios antes. El acuerdo entre él y la Congregazione dello Stato $^{34}$ preveía que desde entonces solo este tribunal fuese el encargado de la recaudación de todos los impuestos para sufragar las pagas, socorros y forrajes del ejército, dejando al margen al hasta entonces todopoderoso Magistrato Ordinario (Maffi, 2010, pp. 244-245).

Dicho acuerdo no solo se limitó a la recaudación de estos impuestos, sino que abarcó el problema del alojamiento de las tropas. Como ya hemos subrayado, la importancia de esta carga para las comunidades explica los intentos realizados para repartirla de manera uniforme sobre los lugares, con la introducción de las egualanze. El fin de la guerra conllevó la intensificación de las peticiones de las comunidades, que pretendían intervenir directamente en la gestión de esta carga. Como el ya definido acomodamiento previo, el objetivo era que la Congregazione se hiciese cargo por medio del sistema del remplazo del reparto de dicha contribución sobre todo el territorio del Estado, dividiendo desde entonces la gestión de la maquinaria militar en dos partes bien distintas ${ }^{35}$.

En la práctica el gobernador ponía en ejecución un viejo proyecto del conde de Fuentes, que en 1605 había encargado por primera vez a un solo municionero el abastecimiento del ejército y la provisión de todos los utensilios para su alojamiento (camas, sábanas, colchones etc.). En aquel año Carlo Perrone firmó un contrato con la Congregazione, por el que se hacía cargo de la tarea de conseguir todo lo necesario para la tropa (Maffi, 2005b, pp. 519-548). Un experimento que resultó muy breve debido a las rivalidades entre varias ciudades y condados, y porque la ciudad de Milán se excusaba del pago de su cuota. Estas razones llevaron a la Congregazione a no renovar el acuerdo y a volver al sistema antiguo del Magistrato Ordinario, quien se hacía cargo del repartimiento de las raciones de alojamiento sobre el territorio ${ }^{36}$.

34 Instituida en 1543 por voluntad del emperador Carlos V, desde hacía poco tiempo señor de Milán, el objetivo primario de la Congregazione dello Stato fue representar los intereses de las comunidades en materia fiscal frente a los perfectos encargados del nuevo estimo generale y a los representantes de las ciudades. Estaba compuesta por nueve oradores, uno por cada ciudad, y nueve síndicos, uno por cada condado y el cargo de presidente lo ejercía el vicario de provisión de la ciudad de Milán. Sobre sus competencias y evolución durante el dominio español (véase, Maffi, 2014, pp. 53-75). «La gran máquina del cargo militar se reparte en dos polos, él una es de las pagas, socorros y forrajes que desde el año 1662 a esta parte se dividen entre las ziudades y provincias con la regla de la porzión expressa en los repartos que salen del oficio del comissario general del exército, el otro es de alojamiento que ymporta tanto quanto es la subministración de muebles y cassas a todo el exército leña a la ynfantería y a los cuerpos de guardia, y que desde el año 1662 a esta parte se a gobernado con la formalidad del arrendamiento que llaman de remplazo»: AGS, Secretarías Provinciales, legajo 2.010, doc. 1, doc. cit.

36 AGS, Secretarías Provinciales, legajo 1.983, doc. 57, Sobre la instituzione del Rimplazzo e continuazione d'esso, sin fecha (pero posterior a 1685) 
La introducción del remplazo eliminó definitivamente el sistema de las egualanze, que nunca habían funcionado y que habían sido una fuente de innumerables quejas entre las ciudades y el campo por el reembolso de los gastos. Además, también había sido motivo de protestas de las ciudades hacia los soldados, que desde entonces se tenían que alojar únicamente en cuarteles y no en casas de particulares ${ }^{37}$, y hacia la Congregazione, que arrendaba el servicio de utensilios a un empresario repartiendo el gasto, convirtiéndose en el supremo árbitro de la situación. Al acabar el contrato, tras cinco años, dicho tribunal efectuaba un nuevo arrendamiento, bajo la supervisión del Magistrato Ordinario, entregando la gestión del servicio a quien había hecho la mejor oferta.

La adopción de estas medidas representó la culminación del proceso de reforma comenzado un siglo antes, que había tenido una brusca aceleración en la primera mitad del siglo XVII, y satisfacía las pretensiones de la Congregazione, además de ser un alivio y un equitativo reparto de los $\operatorname{costes}^{38}$. Gracias a la introducción de estas nuevas normativas, este tribunal se convertía así en el árbitro de todas las cuestiones pendientes relativas al coste de la maquinaria bélica, y en el referente principal entre el gobernador y el Estado en materia de fiscalidad. Una posición de la que abusaría para pedir una serie de nuevas reformas: la reducción de los gastos militares, la destitución de varios funcionarios y que la corte de Madrid emprendiera medidas en contra de los gobernadores que no hubiesen aplicado al pie de la letra las normativas regias introducidas para frenar el aumento de las imposiciones de naturaleza militar, alargando así su esfera de competencia. Tanto que, en palabras de Antonio Álvarez-Ossorio Alvariño, «el fisco sirvió de punto de partida para que el estado expresase su opinión en un amplio repertorio de materias sobre las que no tenía competencias directas» (Álvarez-Ossorio Alvariño, 2002, p. 47).

A pesar de las continuas quejas de las ciudades y comunidades del Estado sobre las continuas solicitudes de contribuciones, se puede afirmar sin problema que el sistema funcionó y permitió la supervivencia del ejército de Lombardía en un periodo de fuerte apuros, con las remesas de España y otros reinos reducidas a un puñado de escudos $^{39}$. Entre 1662 y el 1690 el Estado pagó más de 150.000.000 de liras impe-

37 «Cessando per questo mezzo l'eccessivo costo degli alloggiamenti ne' quartieri aperti, et le grandi spese che erano necessitate le città et terre a fare nei continui transiti, e nelle egualanze provinciali e generali»: AGS, Secretarías Provinciales, legajo 1.983, doc. 57, doc. cit.

38 «Et finalmente conseguendo per questi mezzi si dell'impresa generale sudetta come del riparto generale, che si fa nell'ufficio del commissario generale dell'esercito e Stato la quiete de popoli, e la eguale distribuzione del carico militare»: AGS, Secretarías Provinciales, legajo 1.983, doc. 57, doc. cit.

39 En la segunda mitad del siglo solo en raras ocasiones los envíos de dinero desde Madrid llegaron a superar los 100.000 escudos al año, y en muchos momentos no llegó ningún dinero. Lo mismo se puede decir de las remesas napolitanas, que cayeron en picado reduciéndose a muy poca cosa (véase Maffi, 2010, pp. 210-229). 
riales, con una media de 5.500.000 liras al año, un cargo notablemente superior a las entradas ordinarias del país (Maffi, 2010, p. 252). La eclosión de la guerra conllevó un aumento enorme de los gastos militares. En el verano de 1692, según los cálculos de la Congregazione, se estaban pagando más de 25.000 liras diarias por el ejército ${ }^{40}$. Una carga que estaba destinada a incrementarse en los años siguientes: durante la campaña de 1695 en cuatro meses las comunidades tuvieron que anticipar 2.000.000 de liras $^{41}$. Y en algunas ocasiones, como denunciaba el representante lombardo en la corte, el Estado había contribuido al esfuerzo bélico pagando 2.000.000 de reales de a ocho al año, lo que suponía más de 12.000 .000 de liras ${ }^{42}$.

El final de la guerra en 1697 asistió a una nueva contracción del dispositivo militar: la guarnición fue reducida a poco más de 11.000 soldados en 1698, si bien la grave situación internacional en vísperas de la sucesión hizo que ya al año siguiente el país hospedara a 13.500 hombres. A la muerte de Carlos II el ejército de Lombardía continuó siendo la fuerza de combate más grande de la región, el escudo de Italia, el antemural de Nápoles y Sicilia y el freno de los enemigos del rey. No solo las fuerzas reales eran superiores en número a las del duque de Saboya, universalmente considerado el más poderoso de los soberanos italianos, y de la Serenísima República de Venecia, sino que, seguramente, estaban mucho más organizadas y mejor armadas (Maffi, 2020, p. 319).

\section{Conclusiones}

Como hemos visto en las páginas anteriores, el ejército de Lombardía representó durante toda su existencia la clave del poder hispano en la península italiana. Desde su creación, al tiempo del emperador Carlos, su misión fue de garantizar el control de la llanura Padana y antemuralla del reino de Nápoles, ejerciendo como centinela adelantada y guardia de los pasos alpinos. Objetivos a los cuales se asumieron durante los años del reinado de Felipe II el control de las vías de comunicaciones con Alemania y los Países Bajos. Unas tareas que preveían el empleo de una gran masa de maniobra y rápidamente en la región fue acuartelado el segundo dispositivo militar por importancia de toda la monarquía.

La crisis del siglo XVII afectó también las posiciones hispanas en Italia. Las largas guerras en contra de Francia durante la primera mitad del siglo para la supremacía continental y el deber hacer frente a la política expansionista de Luis XIV pusieron a dura prueba el instrumento militar español en la región. Sin embargo, esta crisis no tuvo las consecuencias nefastas que tradicionalmente han sido pintadas por parte

40 ASCMi, Dicasteri, busta 167, sin foliar, la Congregazione dello Stato al rey, 29 de junio de 1692.

41 AHN, Estado, legajo 1.902, sin foliar, consulta del Consejo de Italia, 18 de agosto de 1695.

$42 \mathrm{AHN}$, Estado, legajo 1.932, sin foliar, consulta del Consejo de Italia, 6 de abril de 1700. 
de generaciones de historiadores. No obstante, las claras dificultades el ejército de Lombardía supo mantener sus posiciones y a finales del siglo todavía representaba un instrumento formidable, bien organizado y equipado. Un éxito que fue posible gracias a la contribución de las comunidades locales que tuvieron que hacerse cargo de las dos terceras partes de todo el gasto militar.

Gracias este conjunto de factores: la flexibilidad el instrumento militar, que supo continuamente innovarse a lo largo de todo el siglo, la capacidad mostrada por parte del alto mando hispano y las copiosas contribuciones pagadas por parte del país (recordamos como solo durante la guerra de los Nueve años los súbditos lombardos pagaron más de 2 millones de reales de a ocho al año, y igualmente copiosa fue la carga que tuvo que afrontar la región durante la guerra de los Treinta años) Carlos II consiguió mantener el control de las vitales posiciones en Italia del Norte.

\section{AGRADECEMENTOS}

La edición de este trabajo ha sido posible gracias a la ayuda del Programa de Grupos de Potencial Crecemento concedida por la Consellería de Cultura, Educación e Universidade da Xunta de Galicia al GI-1921 de la USC (Referencia: GPC, ED 431B 2021/06). 


\section{Bibliografía}

Aldea Vaquero, Quintín (1998), «La Valtellina, tassello strategico nella geopolitica europea della prima metà del secolo XVII», en Borormeo, Agostino (dir.), La Valtellina crocevia dell'Europa. Politica e religione nell'età della guerra dei Trent'anni, Milano, Editoriale Giorgio Mondadori, pp. 3-21.

Allen, Paul C. (2000), Philip III and the Pax Hispanica, 1598-1621, New Haven \& London, Yale University Press.

Álvarez-Ossorio Alvariño, Antonio (2002), La república de las parentelas. El Estado de Milán en la monarquía de Carlos II, Mantova, Arcari Editore.

Álvarez-Ossorio Alvariño, Antonio (2007), «The State of Milan and the Spanish Monarchy», en Dandelet, Thomas J. y Marino, John A. (eds.), Spain in Italy. Politics, Society, and Religion 1500-1700, Leiden \& Boston, Brill, pp. 99-132. $<$ https://doi.org/10.1163/ej.9789004154292.i-606.25>.

BARBERIS, Walter (1988), Le armi del principe. La tradizione militare sabauda, Torino, Einaudi.

Barrio Gozalo, Maximiliano (1998), «La Valtellina, tassello strategico nella geopolitica europea della prima metà del secolo XVII», en Borormeo, Agostino (dir.), La Valtellina crocevia dell'Europa. Politica e religione nell'età della guerra dei Trent'anni, Milano, Editoriale Giorgio Mondadori, pp. 23-51.

Bianchi, Paola (2002), Onore e mestiere. Le riforme militari nel Piemonte del Settecento, Torino, Zamorano Editore.

Buum, Anna (2014), La Diplomatie de la France en Italie du nord au temps de Richelieu et de Mazarin, Paris, Classiques Garnier.

Bombín Pérez, Antonio (1975), La cuestión de Monferrato (1613-1618), Valladolid, Colegio Universitario de Álava, Universidad de Valladolid.

Bombín Pérez, Antonio (1978), «Política antiespañola de Carlos Emanuel I de Saboya», Cuadernos de Investigación Hitstórica, 2, pp. 153-173.

Cano de Gardoqui, José L. (1962), La cuestión de Saluzzo (1588-1601), Valladolid, Universidad de Valladolid.

Cano de Gardoqui, José L. (1973), «Orientación italiana del ducado de Saboya», Hispania, 33, pp. 565-595.

Chabod, Federico (1971a), «Lo stato di Milano e l'impero di Carlo V», en Chabod, Federico, Lo Stato e la vita religiosa a Milano nell'epoca di Carlo V, Torino, Einaudi.

Chabod, Federico (1971b), Storia di Milano nell'epoca di Carlo V, Torino, Einaudi. 
Chabod, Federico (1986), «Milano o i Paesi Bassi? Le discussioni in Spagna all'alternativa del 1544», en Chabod, Federico, Carlo V e il suo impero, Torino, Einaudi, pp. 185-217.

Chittolini, Giorgio (1979), La formazione dello stato regionale e le istituzioni del contado (secoli XIV e XV), Torino, Einaudi.

Covini, Nadia Maria (1992), «Alle spese di Zoan Villano: gli alloggiamenti militari nel dominio visconteo-sforzesco», Nuova Rivista Storica, 76, pp. 1-56.

Elliott, John H. (1984), The Revolts of the Catalans. A Study in the Decline of Spain (1598-1640), Cambridge, Cambridge University Press.

Elliott, John H. (1986), The Count-Duke of Olivares. The Statesman in an Age of Decline, New Haven \& London, Yale University Press.

Elliott, John H. (1988), «Spain ant the War», en Parker, Geoffrie (ed.), The Thirty Years War, London, Routledge, pp. 103-109.

Esteban Estríngana, Alicia (2005), Madrid y Bruselas. Relaciones de gobierno en la tapa postarchiducal (1621-1634), Leuven, Leuven University Press.

ExternnRink, Sven (2000), «"Le cœur du Monde” et la "liberté d'Italie": aspects de la politique italienne de Richelieu 1624-1642», Revue d'Histoire Diplomatique, 114, pp. 181-208

Externbrink, Sven (2014), «L'Espagne, le duc de Savoie et les “portes”, La politique italienne de Richelieu et Louis XIII», en Ferretti, Giuliano (dir.), De Paris à Turin. Christine de France duchesse de Savoie, Paris, L'Harmattan, pp. 15-33.

Fernández Albaladejo, Pablo (1993), Fragmentos de Monarquía, Madrid, Alianza.

Fernández Álvarez, Manuel (1955), Don Gonzalo Fernández de Córdoba y la Guerra de Sucesión de Mantua y del Monferrato (1627-1629), Madrid, CSIC.

Ferretti, Guiliano (2016), «La prima guerra del Monferrato e l'intervento francese», en Merlin, Pierpaolo y Ieva, Frédéric (dirs.), Monferrato 1613. La vigilia di una crisi europea, Roma, Viella, pp. 31-46.

GAL, Stéphane (2012), Charles-Emmanuel de Savoie. La politique du précipice, Paris, Payot.

García García, Bernardo José (1996), La Pax Hispanica. Política exterior del duque de Lerma, Leuven, Leuven University Press.

Giannini, Massimo C. (1997), «Città e contadi dello Stato di Milano nella politica finanziaria del conte di Fuentes (1600-1610)», en Brambilla, Elena y Muto, Giovanni (eds.), La Lombardia spagnola. Nuovi indirizzi di ricerca, Milano, Unicopli, pp. 191-208. 
Guinand, Julien (2020), La guerre du roi aux portes de l'Italie 1515-1559, Rennes, Presses Universitaires de Rennes.

HaLe, John R. (1990), L'organizzazione militare di Venezia nel '500, Roma, Jouvence.

IsRAel, Jonathan I. (1997), «Olivares, the Cardinal-Infante and Spain's Strategy in the Low Countries: The Road to Rocroi, 1635-43», en Israel, Jonathan I., Conflicts of Empires. Spain, the Low Countries and the Struggle for World Supremacy 1585-1713, London, Hambledon Press, pp. 63-91.

Koenigsberger, Helmuth G. (1971), The Habsburgs and Europe 1516-1660, Ithaca y London, Cornell University Press.

MAfFi, Davide (2002), «L'amministrazione della finanza militare nella Lombardia spagnola: i veedores e contadores dell'esercito (1536-1700)», Storia Economica, 5, pp. 51-106.

MAfFi, Davide (2005a), «Confesionalismo y Razón de Estado en la Edad Moderna. El caso de la Valtellina (1637-1639)», Hispania Sacra, 57, pp. 467-490. <https://doi.org/10.3989/hs.2005.v57.i116.107>.

Maffi, Davide (2005b), «Tra asiento e administración. Carlo Perrone e il contratto per il pane di munizione nello Stato di Milano (1605-1615)», Storia Economica, 8, pp. 519-548.

MAFFI, Davide (2007), Il baluardo della corona. Guerra, esercito, finanze e società nella Lombardia seicentesca (1630-1660), Firenze, Le Monnier.

MAFFI, Davide (2010), La cittadella in armi. Esercito, società e finanza nella Lombardia di Carlo II 1660-1700, Milano, FrancoAngeli.

MAfFi, Davide (2014), «El peso de Marte. El sistema del "Remplazo" militar y la “Congregazione dello Stato" en el Milanesado español (1662-1700)», Chronica Nova, 40, pp. 53-75.

MAfFi, Davide (2018), «La guerra olvidada. La estrategia española en la cuestión de Saluzzo (1588-1598)», en Pazzis Pi Corrales, Magdalena de y Cepeda Gómez, José (eds.), Aspectos de la historiografía moderna. Milicia, iglesia y seguridad. Homenaje al Profesor Enrique Martínez Ruiz, Madrid, Actas Editorial, pp. 417-446.

MAfFi, Davide (2020a), Los últimos tercios. El ejército de Carlos II, Madrid, Desperta Ferro Ediciones.

MAfFi, Davide (2020b), «Milán de «corazón de la Monarquía» a frente segundario del desafío franco-español (1613-1659)», en García García, Bernardo José y Maffi, Davide (eds.), El Piamonte en guerra (1613-1659). La frontera olvida$d a$, Madrid, Doce Calles-Fundación Carlos de Amberes, pp. 229-250. 
Maltby, William S. (1983), Alba. A Biography of Fernando Alvarez de Toledo, Third Duke of Alba 1507-1582, Berkeley (Los Angeles)-London, University of California Press.

Manning, Roger B. (2006), An Apprenticeship in Arms. The Origins of the British Army 1585-1702, Oxford, Oxford University Press.

Marrades, Pedro (1943), El camino del Imperio. Notas para el estudio de la cuestión de la Valtelina, Madrid, Espasa Calpe.

Merlin, Pierpaolo (2004), «Saluzzo, il Piemonte, l’Europa. La politica sabauda dalla conquista del marchesato alla pace di Lione», en Fratini, Marco (ed.), L'annessione sabauda del marchesato di Saluzzo. Tra dissidenza religiosa e ortodossia cattolica secc. XVI-XVIII, Torino, Claudiana, pp. 16-61.

Merlin, Pierpaolo (2016), «Il Monferrato. Un territorio strategico per gli equilibri europei del Seicento», en Merlin, Pierpaolo y Ieva, Frédéric (dirs.), Monferrato 1613. La vigilia di una crisi europea, Roma, Viella, pp. 15-29.

Merlin, Pierpaolo (2018), La croce e il giglio. Il ducato di Savoia e la Francia tra XVI e XVII secolo, Roma, Carocci.

Mesa Gallego, Eduardo de (2020), «El ejército de la Monarquía Hispánica y la guerra de Monferrato (1614-1617)», en García García, Bernardo José y Maffi, Davide (eds.), El Piamonte en guerra (1613-1659). La frontera olvidada, Madrid, Doce Calles-Fundación Carlos de Amberes, pp. 127-156.

Micallef, Fabrice (2014), Un désordre européen. La compétition internationale autour des «affaires de Provence» (1580-1598), Paris, Publications de la Sorbonne.

PARKER, Geoffrey (1986), «España, sus enemigos y la revuelta de los Países Bajos (1559-1648)», en Parker, Geoffrey, España y los Países Bajos 1559-1659, Madrid, Rialp.

PARKer, Geoffrey (1990), The Army of Flandes and the Spanish Road 1567-1659, Cambridge, Cambridge University Press.

PARKer, Geoffrey (1994), «The Making of Strategies in Habsburg Spain: Philip II's “bid for mastery", 1556-1598», en Murray, Williamson, McGregor Knox y Alvin Bernstein (eds.), The Making of Strategy: Rulers, States, and War, Cambridge, Cambridge University Press, pp. 115-150.

PARKer, Geoffrey (2004), The Army of Flanders and the Spanish Road 1567-1659, Cambridge, Cambridge University Press.

Parrott, David (1997), «The Mantuan Succession, 1627-31: A Sovereignty Dispute in Early Modern Europe», English Historical Review, 112, pp. 20-65. <https:// doi.org/10.1093/ehr/CXII.445.20>. 
Quatrefages, René (1996), La revolución militar moderna. El crisol español, Madrid, Ministerio de Defensa.

Quazza, Romolo (1926), La guerra per la successione di Mantova e del Monferrato (1628-1631), Mantova, Casa Editrice G. Mondovì, 2 vols.

RABÀ, Michele Maria (2016), Potere e poteri. "Stati”, "privati” e comunità nel conflitto per l'egemonia in Italia settentrionale (1536-1558), Milano, FrancoAngeli.

Ribot García, Luis (1990), «Milán, Plaza de Armas de la Monarquía», Investigaciones históricas. Época moderna y contemporánea, 10, pp. 203-238.

Ribot GARcía, Luis (1994), «Las provincias italianas y la defensa de la Monarquía», en Musi, Aurelio (ed.), Nel sistema imperiale l'Italia spagnola, Napoli, Edizioni Scientifiche Italiane, pp. 67-92.

Rizzo, Mario (1995), «Finanza pubblica, impero e amministrazione nella Lombardia spagnola: le "visitas generales"», en Pissavino, Paolo y Signorotto, Gianvittorio Signorotto (eds.), Lombardia Borromaica Lombardia Spagnola 1554-1659, Roma, Bulzoni, vol. 2, pp. 303-361.

Rizzo, Mario (2001), Alloggiamenti militari e riforme fiscali nella Lombardia spagnola fra Cinque e Seicento, Milano, Unicopli.

Rizzo, Mario (2003), «Il processo di perequazione degli oneri militari nella Lombardia cinquecentesca», en Rizzo, Mario, Ruiz Ibáñez, José Javier, y Sabatini, Gaetano (eds.), Le forze del principe. Recursos, instrumentos y límites en la práctica del poder soberano en los territorios de la Monarquía Hispánica, Murcia, Universidad de Murcia, vol. 2, pp. 469-538.

Rizzo, Mario (2007), «Porte, chiavi e bastioni. Milano, la geopolitica italiana e la strategia asburgica nella seconda metà del XVI secolo», en Cancila, Rossella (ed.), Mediterraneo in armi (secc. XV-XVIII), Palermo, Mediterranea, vol. 2, pp. 467-511.

Rodríguez-Salgado, Mía (1994), Metamorfosi di un impero. La politica asburgica da Carlo V a Filippo II (1551-1559), Milano, Vita \& Pensiero.

Signorotto, Gianvittorio (1989), «Milano e la Lombardia sotto gli spagnoli», en Storia della società italiana. La Controriforma e il Seicento, Milano, Teti editore, vol. 11, pp. 189-223.

Storrs, Christopher (1997), «The Army of Lombardy and the Resilience of Spanish Power in Italy in the Reign of Carlos II (1665-1700)», War in History, 4, pp. 371-397. <https://doi.org/10.1177/096834459700400401>.

Storrs, Christopher (1998), «The Army of Lombardy and the Resilience of Spanish Power in Italy in the Reign of Carlos II (1665-1700)», War in History, 5, pp. 1-22. <https://doi.org/10.1177/096834459800500101>. 
StradLInG, Robert A. (1992), Europa y el declive de la estructura imperial española 1580-1720, Madrid, Cátedra.

TAPIÉ, Victor-Lucien (1989), La guerre de Trente Ans, Paris, Sedes.

Vermeir, René (2006), En Estado de guerra. Felipe IV y Flandes 1629-1648, Córdoba, Editorial Universidad de Córdoba.

Vigo, Giovanni (1979), Fisco e società nella Lombardia del Cinquecento, Bologna, Il Mulino.

Wood, James B. (2002), The King's Army. Warfare, soldiers, and Society during the Wars of Religion in France, 1562-1576, Cambridge, Cambridge University Press. 